\title{
Joined forces in person-centered care in the intensive care unit: a case report from the Netherlands
}

\author{
Margo M. C. van Mol 1,5*, Marianne Brackel ${ }^{5}$, Erwin J. O. Kompanje ${ }^{1}$, Lorette Gijsbers ${ }^{2,5}$, Marjan D. Nijkamp ${ }^{3}$,
} Armand R. J. Girbes ${ }^{4,5}$ and Jan Bakker ${ }^{1,6}$

\begin{abstract}
Aim: First, to describe the state of the art of joined forces in person-centered care of professionals and patients with their relatives, in the context of intensive care units (ICUs) in the Netherlands. Second, to explore the aspects that are relevant to the professionals providing this compassionate care.

Background: Person-centered care is gaining increasing interest, with the shift from provider-centric norms to care arranged around individual beliefs and needs. Current daily practice in the ICU corresponds increasingly to this idea of person-centered care.

Case presentation: The realization of 'best practices' in the emotional support of ICU patients' relatives in three hospitals in the Netherlands enables the sharing of the successful ICU quality improvements nationwide. While other organizations have implemented similar evidence-based interventions, it seemed that professionals were sometimes inclined to reinvent the wheel as they were not aware of other successful initiatives and results. The 'Family and patient Centered Intensive Care' (FCIC) foundation acts as a center of expertise, aiming to exchange knowledge, to maintain (inter)national contacts, and is an inspirational force in reducing the emotional effects of ICU admission on patients and their relatives.

Conclusion: Quality improvement programs to support the emotional distress of an ICU admission are ideally designed combining the strengths of different disciplines and involving patient-experts and their relatives. This approach is the core of person-centered care; the views, values and needs of the experts are the basis of change in ICU policies. FCIC ensures that these joined forces of professionals and experts improve the quality of care during and after ICU admission. However, person-centered care puts an additional emotional effort on the shoulders of the ICU professionals. This needs to be recognized as well.
\end{abstract}

Keywords: Person-centered care, Patient-centeredness, Compassion, Intensive care unit, Patient-experts, ICU professionals

\section{Background}

Person-centered care is gaining increasing interest, with the shift from provider-focused norms to care that is focused on individual beliefs and needs [1-3]. So called "paternalistic healthcare" focuses on an 'I know what is the best for you' approach, whereas person-centered care

\footnotetext{
*Correspondence: m.vanmol@erasmusmc.nl

1 Department of Intensive Care Adults, Erasmus MC University Medical Center, Room H 1005, PO Box 2040, 3000 CA Rotterdam, The Netherlands

${ }^{5} \mathrm{FCIC}$ (Family and Patient Centered Intensive Care) Foundation, Tiel, The Netherlands

Full list of author information is available at the end of the article
}

emphasizes an equal relationship with the patient and a holistic approach that can be summarized as 'What can I do to improve your health?' [4]. It is therefore essential to involve the individual as an active partner in professional care and treatment [5]. However, patients admitted to the intensive care unit (ICU) are typically not able to receive any information or make decisions due to the severity of their medical conditions or the administration of sedative medications. Thus leaving their relatives as surrogate decision makers. For this reason, professionals in the ICU increasingly view the patient as an integral part 
of a family unit and subsequently include the care provided to the patient with the experiences of their loved ones as well (i.e., family members and close friends visiting the patient) [6-9]. Person-centered care considers patients and their relatives as equal partners in planning, developing and monitoring care to make sure it meets their needs. It includes elements such as respect, compassion, involvement of close relatives, communication, physical comfort and the supply of emotional support [10]. Current daily practice in the ICU increasingly corresponds to this idea of person-centered care, although occasionally, terms such as person-focused care, patient- and family-centered care, relationship-centered care, humanizing care, individualizedcare, or family-oriented care, are used interchangeably $[4,11-13]$. The central objective of all of these concepts is the inclusion of the persons' individual experiences to preserve or improve the quality of care $[14,15]$. This means seeing them as valuable persons, working alongside professionals to get the best outcome.

Communication is a complex two-way process in which the relatives must be respected as a part of the team. Not only to provide information on the severity of illness and targeted medical treatment goals, also to discuss the preferences and values in personal life of the patient. For example, a relative providing the intensivist personal information on the health status of her husband before admission into the ICU, might be valuable for targeting the medical aims of treatment. Cronenwett et al (2007) defined person-centered care as follows: "recognize the patient or designee as the source of control and a full partner in providing compassionate and coordinated care based on respect for patient's preferences, values and needs" $[4,16]$. It is foreseen that in the near future communication and sharing of treatment goals will be considered as important as technical targets in the ICU [15]. This shared decision making might be burdensome for relatives as well. The importance of clear communication in a timely and understandable manner to the person being treated and their relatives, might support the coping mechanism managing the stressful surroundings and critically unstable situation. For example, to the patients, professionals can respect individual preferences and choices in bathing, waking and sleep times, visiting hours and privacy [13]. Professionals can support the relatives discussing on general information, talking over possible emotional and cognitive consequences, recovering from a delier or the revalidation process of their loved ones ahead. As this conversations particularly provide time and space on the emotional impact of the situation, ICU professionals can react to feelings of anxiety, frustration or grief. Being present, allowing silence, using of touch and being sensitive to worries of the relatives are important attitudes to relieve the burdens.
Because the patient's survival has priority, personcentered care in the ICU requires a high level of clinical expertise, far-reaching knowledge, and extensive 'soft-skills' on the parts of the professionals. A change in professional attention is desirable in the highly technical ICU environment and could potentially lead to positive feedback from the patients and relatives $[10,17]$. This feedback might increase satisfaction with healthcare and the assessments of the overall quality of care in the $\operatorname{ICU}[13,18,19]$.

\section{Study aim}

The aims of this case report are 1) to describe the state of the art of joined forces in person-centered care of professionals and patients with their relatives, in the context of intensive care units (ICUs) in the Netherlands, and 2) to explore the aspects that are relevant to the professionals providing compassionate care.

\section{Keys concepts in person-centered care Holistic, individual, respectful and empowering}

Morgan and Yoder (2011) identified in a concept analysis of person-centered care the four most associated attributes in a post-acute healthcare setting, namely: holistic, individual, respectful and empowering [13]. This framework provides the context of current study. Providing holistic care allows the professionals to better understand the entire person and how to respond to their needs. Through individualized care, the professionals recognize and meet the unique personality of people and their perspectives. Being respectful is approaching the patients and their relatives as active health care consumers with own choices in receiving support and care. Effective communication and collaboration are needed for a person to sincerely feel empowered to be involved in healthcare decisions [13].

\section{Compassion}

Another key concept in person-centered care is compassion [20, 21]. Compassion is a relational caring activity for other human beings. It involves experiencing an emotional reaction and noticing when someone is suffering, thus stimulating meaningful action in the relationship. Compassion has traditionally been related to most major religions [22]. It can be described as the sensitivity to another's pain, concerns or distress coupled with a deep desire taking action to ameliorate them $[3,22]$. A compassionate attitude requires attention to cultural aspects, beliefs, behaviors and personal needs. According to Youngson (2012), compassion is feeling the pain as your own; it is mutual. The provider and receiver are one, similar to the concept of 'open-hearted compassion with non-attachment' [23]. However, healthcare professionals trying to alleviate that pain, should not claim ownership. 
Additionally, this mutual feeling might have a too demanding emotional effort on the ICU professionals, which needs to be recognized as well.

\section{Empathy}

As a closely related concept, empathy is the cognitive understanding of other human beings in which caregivers do not have to feel the pain and suffering of their patients [24, 25]. Acknowledgements of the patient's pain and suffering with understanding, kind words of sympathy, and the display of a profound interest in the person lying in the hospital bed are factors that are as important as the medical and nursing care per se. The meaning of empathy begins from the philosophy of aesthetics and was first applied by German philosophers as 'Einfühling' [26]. It characterizes the human ability to get 'inside' a beautiful piece of art, for example a painting or a piece of music. It was the psychologist Tichener who adapted this word and first used empathy in 1909 [27]. The idea of getting into a feeling is vital in human nature, particularly to see and feel the world form the other's perspective trying to understand and relate with those in the nearby surroundings [26]. Empathy covers three dimensions [28]: 1) cognitive empathy is the ability to perceive, recognize and discriminate emotional states in the other person; 2) affective empathy is the feeling or the experience of the other's emotional state; 3 ) perspective taking, also known as Theory of Mind, metalizing and mind-reading, is seeing things from the other person's point of view [29].

A critical review stated that the majority of the 38 identified measurement instruments lacked a clear definition of empathy and were based on aspects relatively far away from daily healthcare practice [30]. For example, an item used in the Jefferson Scale of Physician Empathy is: 'I do not enjoy reading non-medical literature or experiencing the arts'. The majority of the explored studies in the critical review applied neither a cognitive nor an affective perspective of empathy, although some studies explicitly adhered to a cognitive process. From a phenomenological background, empathy is the one-sided cognitive awareness and imaginative perspective taking of others in contrast to the two-sided sharing of affects [31].

Studies in neuroscience have explored brain regions related to empathy [29]. The results indicate an activation in special areas, e.g., the anterior insula and anterior cingulate cortex, when participants empathized with people in pain. However, some factors might modulate empathy [29]. These factors are the intensity of displayed emotion, attention, situational context, features of the target, and characteristics of the empathizer. These characteristics in particular might play a role in healthcare providers. It is shown that physicians, compared to naive participants, have reduced empathic brain responses when seeing animated pictures of needles being inserted into the human body [29]. To conclude, empathy is resonating with another person's feelings. It is the basic of holistic, individualized and respectful caring in an empowering way.

In contrast, sympathy is "an emotional response stemming from another's emotional state or condition that is not identical to the other's emotion, but consist of feelings of sorrow or concern for another's welfare" [32]. Therefore, sympathy is me-oriented while empathy is you-oriented. In addition, persons who feel sympathy might have difficulty to detach own feelings from the others' while persons experiencing empathy are able to detangle themselves from others [33, 34].

\section{Case presentation Joined initiative}

Citation: "Last year, my father was acutely admitted to the ICU with a septic shock, resulting from an anastomotic leak following bowel tumor surgery. His situation remained instable for two weeks. This period was a rollercoaster for our family, constantly juggling with hope and fear. It was also a time where we had to rely on each other in order to cope with the stressful events, understand the provided information, make choices and to look for ways to continuously supporting my father while keeping ourselves afloat" [35].

Relatives can become confused and anxious due to the stressful environment of the ICU [36-38]. The admission into the ICU may have physical, cognitive, and psychological consequences in the long term for patients and psychological consequences for relatives as well. Therefore, three ICUs in the Netherlands jointly implemented new interventions in a quality improvement program to support relatives in the ICU (Spaarne Hospital in Haarlem, Gelderse Vallei in Ede, and Erasmus MC in Rotterdam). Some examples of these interventions are: prolonged visiting hours, encouragement of the relatives to keep a diary, a deferred intake interview with a close relative to provide information and discuss the emotional impact, a personalized poster with pictures and other personal facts of the patient, an individual tailored ICU-webportal, and the introduction of weekly multidisciplinary psychosocial rounds. The effects of these interventions on the quality of care as perceived by the relatives were measured using the Consumer Quality Index 'Relatives in the ICU', which is a validated Dutch questionnaire for measuring person-reported outcomes $[18,39]$. It is important to involve all disciplines, including nurses, physicians, social workers, chaplains, psychologists, quality advisors, and a clinical ethicist, in this process of person-centeredness in the ICU. 


\section{Knowledge exchange and patient-experts}

Citation: "Fantastic, to feel so much energy [throughout the 'Open Space meeting'] to formalize the recognition, facts and improvements during and after an ICU admission. It brought up a lot in me, I needed some time to react. The ICU period has more impact on daily life than you can think of. Powerful, all of us together!' [40].

Best practices in the support of ICU patients' relatives in three hospitals in the Netherlands enables the sharing of the successful ICU quality improvements with colleagues at national symposia. Other organizations have similarly implemented several evidence-based interventions [17, 41-44]. However, during these symposia it seemed that professionals were occasionally inclined to reinvent the wheel because they were not aware of other successful initiatives and results. For example, the provision of a general information leaflet about the effects of an ICU admission has been an isolated effort in many hospitals, although the contents were similar across hospitals. Extensive knowledge exchange regarding daily practices is therefore desirable; however, a useful communication platform was lacking.

The original joint initiative also provided an impetus to the development and implementation of evidence based interventions to reduce the emotional influence of ICU admission for both patients and relatives in a nationwide collaboration. For example, to gather, improve and disseminate professional activities to prepare and support the visit of children to their loved ones in the ICU. Additionally, this initiative was the beginning of a structural involvement of field-experts, active and passionate ex-ICU patients and relatives, which has not been set up in this style previously.

\section{Foundation Family and patient Centered Intensive Care}

The nationwide collaboration of professionals and fieldexperts resulted in the Family and patient Centered Intensive Care (FCIC) foundation in January 2015. The FCIC acts as a center of expertise, aiming to exchange knowledge, maintain (inter)national contacts, and to inspire the professionals reducing the impact of an ICU admission in patients and their relatives. Moreover, other professionals and field-experts disseminate additional empirical examples and informational material via the FCIC. A strength of the FCIC is this structural collaboration, the exchange of knowledge and daily practices with field-experts.

\section{Future targets of the $\mathrm{FCIC}$}

Citation: "It wasn't easy, those weeks. So much grief in me about my lost health and my dark and uncertain future. About my former work which I loved so dearly. Grief over the critical days in the ICU of which I know only from hearsay, about the bewildering and scary events during the following days. Grief about my prednisone face and moth-eaten hair, the incredible fatigue and about all my thoughts 'What: if-then'. About the long, heavy, and tough beautiful year in the medical rehabilitation center. About the worries and sorrows for my family, my kin and parents. My tears come in waves; minutes, hours, days, weeks in succession. I gave way to it, knowing I need time to shed all those tears and to bury my grief with love and tender care. Again, I count my blessings; there are so many people wanting to listen, willing to help, and really being able to help me to come over all the incredible events of the past one and a half year" [45].

Recently, Post Intensive Care Syndrome (PICS) has been recognized as a syndrome to emphasize the long term consequences of admission into the ICU $[46,47]$. In addition to challenges in recovering from the underlying critical illness and physical rehabilitation, emotional distress also needs to be addressed. Sustained support for both the patients and their relatives after the ICU period is frequently lacking [15]. This gap might be due to insufficient knowledge about the physical, emotional, and cognitive consequences of the ICU experience in general ward nurses, general practitioners and the healthcare insurance companies. In general, quality improvement programs of ICU aftercare are ideally designed combining the strengths of different disciplines and involving patientexperts. This approach is the core of person-centered care; the views, values and needs of the experts are the basis of change in ICU policies. For example, patient-experts in FCIC have launched a powerful lobby to introduce aftercare inside and outside the direct work field. This raised the awareness of healthcare organizations, as stated in personal correspondence, to address the long term health problems.

Another target is the involvement of field-experts through innovative methods, such as social media or web applications. Inspiring examples are the communication app 'voICe' for intubated patients [48], the general support app 'MyICU', which serves as a communication tool to better engage ICU patients and family members in decisions [49], and the webportal 'IC Portal' in which relatives and family members receive tailored information, can keep a journal, plan visits, and request family conversations [50]. These applications should relate to the person's cultural background, health literacy level and communication needs. An important point is understanding and speaking the same language as expert and professional. The development of a well-designed, easy accessible, safe and wide-ranging web application to support and mobilize field-experts is a work in progress for the FCIC.

The FCIC ensures that field-experts are heard via story-telling and active participation in a fully integrated network. The FCIC will convey the idea of personcentered care. 


\section{Discussion}

Citation: 'I don't think the word 'dehumanize' is an intentional action. It is a result of doctors and nurses being so committed to numbers and treatment that there can be a disconnection with the patient. In my own experience in the MICU [medium intensive care unit], I was in a nowhere bubble with no past, present, future, or hope. I could only imagine what their world was like not being in my condition. I knew nothing and felt I was being told nothing and it was the lowest I have ever felt. But then my physical therapist introduced himself with an everyday greeting and his name. I was here, and I was real, and I was a person! Hope had found its way to me. That one action improved my mood like nothing else. There was much to be done and my understanding was still nowhere to be found but that greeting was the initial cut in that bubble. The doctors and nurses were amazing, they saved me, and here I am and able to type this because of them. Maybe dehumanizing is the base effort to get someone living again and the focus and efforts surrounding that. However, once that base effort is no longer needed humanizing should come once again to the fore" [51].

FCIC foundation expresses person-centered care with an empathic attitude in holistic, individualized and respectful caring in an empowering way. FCIC foundation stimulates the professionals to better understand the ICU patients and their relatives through storytelling and intensive cooperation. As a consequence, the professionals recognize and meet the unique personality of people and their perspectives. FCIC foundation is the binding factor between professionals and the patients and their relatives. These joined forces are empowering the frail persons to speak up and feel listened to.

A few aspects that are relevant to the professionals providing compassionate care need more discussion. The presented case study provides some grasp on person-centered care based on the transformation towards the holistic vision and application of an empathic attitude in daily practice. An adjustment of the current common approach to patients and relatives in terms of a change toward an organizational culture based on person-centeredness is needed. This approach will alter the relationship between professionals and patients and their relatives from 'caring for' to 'collaborating with'. A starting point is to acknowledge and respect the person in the whole. Still, professional attitudes in personcentered care require a multidisciplinary cultural change, that is broadly supported by all professionals $[4,52]$.

Too much compassion might upset healthcare providers emotionally, sometimes leading to burnout and compassion fatigue $[53,54]$. This process, in turn, can lead to professionals ultimately leaving their job and influence society via lost economic investment [55]. A concept at the other end of the spectrum is dehumanization, or deindividuation [56]. This process emphasizes the need of caregivers to regulate the negative emotions linked to human suffering, deterioration, and dying [57]. Subtle dehumanization of patients may be a protective mechanism with which professionals cope with negative and devastating inhuman situations [58]. To dehumanize a person has a dark meaning; however, it is not meant to emphasize a malicious intent on the part of the professionals. In this case report, dehumanization refers to an unconscious cognitive functioning, a manner in which humans' evolved minds interact with the social practices and functional requirements of hospitals [57]. Especially in an ICU, work is incredibly demanding both physically and emotionally, due to the need to continuously and vigilantly monitor of the patient, the unpredictable life-threatening changes in patient conditions, the use of life-sustaining highly technological strategies, and obtrusive family presence [59]. Although dehumanization never must be encouraged, it is a known side-effect of working in an ICU and a common practice in the work of physicians and nurses. At the same time, solutions to reduce dehumanization have to be stimulated. For example, practitioners should talk to patients and relatives not only about the atelectasis, blood values, and failing organs, but also about how the patient feels, what his/her values and desires are, and what type of work he/she does (or did). Talk among professionals not merely about the disease or 'the interesting X-ray in box one', but call the patient by name in acknowledging the person he/she is. Thus, the goal is to personalize the patient in an environment in which professionals who focus on failing organs and organ systems are busy with life-saving work. Relatives can re-humanize their loved ones as well through reassurance, trust, telling personal stories or news reading.

Empathic concern, as opposed to detached concern, which has been promoted among nurses and physicians in previous decennia [60], refers to the motivation to care for persons in need [61]. Empathic concern allows professionals to change their perspectives and fit the provided care to the specific values, preferences, and needs of the individuals. The ability to feel concern has deep evolutionary roots that are anchored in interacting neural circuits, including the brainstem, amygdala, hypothalamus and somatosensory cortex [62]. According to Decety et al. (2014), the patterns of neural response is highly flexible and can be modulated by a number of contextual, cognitive, social and interpersonal factors $[61,62]$. For example, the neurophysiological response to the perception of another person's pain involves significantly less arousal in brain areas in physicians than in non-physicians. Therefore, not feeling patients' misery might be a natural, unconscious coping process in 
healthcare professionals. Consequently, compassionate caring in the definition of sharing mutual feeling might not be desirable in the stressful environment of ICU professionals. Additionally, sympathy must be restrained in clinical situations whereas empathic communication should be used in all patient related contacts. Although some authors will disagree, the same difference might be true for compassion $[29,33,34]$. Knowing a person's suffering, without specifically feeling the distress, and alleviating that suffering to the best of a practitioner's professional ability through presence and the provision support is a valuable contribution to person-centered care.

Both compassionate caring as well as the all-encom passing process of dehumanization might have negative consequences for ICU professionals themselves; therefore, supportive strategies to protect the health of the professionals are necessary. To meet the needs of professionals and to acknowledge their emotional well-being is a key aspect when providing person-centered care in the ICU [10, 63]. The most important factor might be an open communication to explore emotional experiences among the professionals. This goal can be achieved by informal talks, interventions from social workers or psychologists, and discussion groups regarding topics such as a moral deliberation. Additionally, training in 'soft-skills', including relationship-building and communication capabilities, is an essential element for the development of an empathic attitude in ICU professionals. Furthermore, recognition on the parts of management and policymakers of the efforts to provide person-centered care is a well-intentioned condition. These strategies will improve the better balance for professionals between highly technical ICU care and seeing the patient as the person he/she is.

\section{Conclusion}

The FCIC foundation is a beautiful example of personcentered care in the world of ICU care. On the one hand, professionals must respond to the suffering and needs of patients and relatives with empathy, compassion, and sensitivity inherent for person-centered care. They need to do more than simply know persons are suffering; they have to alleviate that suffering to the best of their abilities and should be able to be there as a witness and to provide support through their presence. On the other hand, excessive immersing with ICU patients and their relatives or an overload of proximity might lead to numbness and emotional exhaustion. Empathic caring is about finding a delicate balance for each individual professional.

\section{Abbreviations}

FCIC, Foundation Family and Patient Centered Intensive Care; ICU, intensive care unit

\section{Acknowledgments}

We are grateful to the core members of FClC for their contribution and support; llona Blauw (Organizational expert, Veilig Veranderen'), Nikk Conneman (Neonatologist, Erasmus MC, Rotterdam), Ruud Klercks (Expert), Grietje Marten-van Steijn (After-care nurse, RadboudUMC, Nijmegen), Hanneke Oonk (Health care coach), Willem Roudijk (Patient coach, RadboudUMC, Nijmegen), Marike van der Schaaf (Associate professor, Revalidation AMC, Amsterdam), Marjolein Siebel (Expert), Idelette Nutma (Expert), Marijke van der Steen (Intensivist, Gelderse Vallei, Ede), Lisbeth Verharen (Associate Professor LAIZ, Nijmegen), John van Vlijmen (Quality advisor and ICU nurse, Ziekenhuis Rivierenland, Tiel), Gijs de Vos (Expert), Peter Westerduijn (ICU nurse, Admiraal de Ruyter Ziekenhuis, Goes). Furthermore, we gratefully acknowledge Herma Speksnijders (ICU nurse Erasmus MC) and Arie den Ouden (Project 'Surgeon', Ambidexter Management) for advice and comments on this case report.

\section{Authors' contributions}

MvM drafted the manuscript, $L G$ and MB contributed to the case report, $L G, M B, E K, M N, A G$ and JB contributed to the discussion and improving the manuscript. All authors read and approved the final manuscript. All cited persons agreed to include their public statements.

\section{Competing interests}

The authors declare that they have no competing interests. This research received no specific grant from any funding agency in the public, commercial or not-for-profit sectors.

\section{Author details}

'Department of Intensive Care Adults, Erasmus MC University Medical Center, Room H 1005, PO Box 2040, 3000 CA Rotterdam, The Netherlands. ${ }^{2}$ Department of Intensive Care, Spaarne Gasthuis, Haarlem, Netherlands. ${ }^{3}$ Faculty of Psychology and Educational Sciences, Open University of the Netherlands, Heerlen, Netherlands. ${ }^{4}$ Department of Intensive Care, University hospital VU medical center, Amsterdam, Netherlands. ${ }^{5} \mathrm{FCIC}$ (Family and Patient Centered Intensive Care) Foundation, Tiel, The Netherlands. ${ }^{6}$ Department of Medicine, Division of Pulmonary, Allergy, and Critical Care Medicine, Columbia University Medical Center, New York, USA.

Received: 3 December 2015 Accepted: 18 May 2016

Published online: 28 May 2016

\section{References}

1. Frampton SB, Guastello S. Time to embrace a New patient-centered care rallying Cry: "Why Not?". Patient-Patient-Centered Outcomes Res. 2014:7(3):231-3.

2. Starfield B. Is patient-centered care the same as person-focused care? Permanente J. 2011:15(2):63.

3. Lown BA, McIntosh S, Gaines ME, McGuinn K, Hatem DS. Integrating Compassionate, Collaborative Care (the" Triple C") Into Health Professional Education to Advance the Triple Aim of Health Care. Acad Med. 2015.

4. Barnsteiner J, Disch J, Walton M: Person and Family Centered Care. Indianapolis: Sigma Theta Tau; 2014.

5. Ekman I, Swedberg K, Taft C, Lindseth A, Norberg A, Brink E, Carlsson J, Dahlin-Ivanoff S, Johansson I-L, Kjellgren K. Person-centered care-Ready for prime time. Eur J Cardiovasc Nurs. 2011;10(4):248-51.

6. Al-Mutair AS, Plummer V, O'Brien A, Clerehan R. Family needs and involvement in the intensive care unit: a literature review. J Clin Nurs. 2013:22(13-14):1805-17.

7. Azoulay E, Pochard F, Chevret S, Lemaire F, Mokhtari M, Le Gall J-R, Dhainaut JF, Schlemmer B. Meeting the needs of intensive care unit patient families: a multicenter study. Am J Respir Crit Care Med. 2001;163(1):135-9.

8. Jacobowski NL, Girard TD, Mulder JA, Ely EW. Communication in critical care: family rounds in the intensive care unit. Am J Crit Care. 2010;19(5):421-30.

9. O'Connell E, Landers M. The importance of critical care nurses' caring behaviours as perceived by nurses and relatives. Intens Crit Care Nurs. 2008;24(6):349-58.

10. Jakimowicz S, Perry L. A concept analysis of patient-centred nursing in the intensive care unit. J Adv Nurs. 2015.

11. Pediatrics AAo. Policy statement. Patient- and family-centered care and the Pediatrician's role. Pediatrics. 2012;129:394-404. 
12. Bardes CL. Defining "patient-centered medicine". N Engl J Med. 2012;366(9):782-3.

13. Morgan S, Yoder LH. A concept analysis of person-centered care. J Holist Nurs. 2012;30(1):6-15.

14. Tzelepis F, Sanson-Fisher RW, Zucca AC, Fradgley EA. Measuring the quality of patient-centered care: why patient-reported measures are critical to reliable assessment. Patient Preference Adherence. 2015;9:831.

15. Cabrini L, Landoni G, Antonelli M, Bellomo R, Colombo S, Negro A, Pelosi P, Zangrillo A. Critical care in the near future: patient-centered, beyond space and time boundaries. Minerva Anestesiol. 2015.

16. Cronenwett L, Sherwood G, Barnsteiner J, Disch J, Johnson J, Mitchell P, Sullivan DT, Warren J. Quality and safety education for nurses. Nurs Outlook. 2007:55(3):122-31.

17. Davidson JE, Powers K, Hedayat KM, Tieszen M, Kon AA, Shepard E, Spuhler V Todres ID, Levy M, Barr J. Clinical practice guidelines for support of the family in the patient-centered intensive care unit: American College of Critical Care Medicine Task Force 2004-2005. Crit Care Med. 2007:35(2):605-22.

18. van Mol M, Bakker EC, Nijkamp MD, Kompanje EJ, Bakker J, Verharen L. Relatives' perspectives on the quality of care in an Intensive Care Unit: The theoretical concept of a new tool. Patient Educ Couns. 2014;95(3):406-13.

19. Heyland DK, Rocker GM, Dodek PM, Kutsogiannis DJ, Konopad E, Cook DJ, Peters S, Tranmer JE, O'Callaghan CJ. Family satisfaction with care in the intensive care unit: results of a multiple center study*. Crit Care Med. 2002;30(7):1413-8.

20. McCormack B, McCance TV. Development of a framework for personcentred nursing. J Adv Nurs. 2006;56(5):472-9.

21. Todres L, Galvin KT, Holloway I. The humanization of healthcare: a value framework for qualitative research. Int I Qual Studies Health Well Being. 2009:4(2):68-77.

22. Papadopoulos I, Shea S, Taylor G, Pezzella A, Foley L. Developing tools to promote culturally competent compassion, courage, and intercultural communication in healthcare. J Compassionate Health Care. 2016;3(1):1.

23. Youngson RA. Time to care: How to love your patients and your job. USA: Rebelheart Publishers; 2012.

24. Pedersen R. Empathy: a wolf in sheep's clothing? medicine. Health Care Philos. 2008:11(3):325-35.

25. Halpern J. What is clinical empathy? J Gen Intern Med. 2003;18(8):670-4.

26. Howe D. Empathy: what it is and why it matters. Basingstoke: Palgrave Macmillan; 2012

27. Titchener EB: Lectures on the experimental psychology of thought processes. JSTOR. 1910

28. Feshbach ND. 12 Parental empathy and child adjustment/maladjustment. Empathy Dev. 1990;271.

29. Hein G, Singer T. I feel how you feel but not always: the empathic brain and its modulation. Curr Opin Neurobiol. 2008:18(2):153-8.

30. Pedersen R. Empirical research on empathy in medicine-A critical review. Patient Educ Couns. 2009;76(3):307-22.

31. Zahavi $D$, Rochat P. Empathy ₹ sharing: perspectives from phenomenology and developmental psychology. Conscious Cogn. 2015.

32. Eisenberg N, Miller PA. The relation of empathy to prosocial and related behaviors. Psychol Bull. 1987;101(1):91.

33. Neumann M, Bensing J, Mercer S, Ernstmann N, Ommen O, Pfaff H. Analyzing the "nature" and "specific effectiveness" of clinical empathy: a theoretical overview and contribution towards a theory-based research agenda. Patient Educ Couns. 2009;74(3):339-46.

34. Batson CD, Eklund JH, Chermok VL, Hoyt JL, Ortiz BG. An additional antecedent of empathic concern: valuing the welfare of the person in need J Pers Soc Psychol. 2007;93(1):65.

35. Marjan: (patients' relative-expert). www.opeenicliggen.nl; 2013.

36. Ågård AS, Harder I. Relatives' experiences in intensive care—Finding a place in a world of uncertainty. Intens Crit Care Nurs. 2007;23(3):170-7.

37. Davidson JE, Jones $\mathrm{C}$, Bienvenu OJ. Family response to critical illness: postintensive care syndrome-family. Crit Care Med. 2012;40(2):618-24.

38. McAdam JL, Fontaine DK, White DB, Dracup KA, Puntillo KA. Psychological symptoms of family members of high-risk intensive care unit patients. Am J Crit Care. 2012;21(6):386-93.

39. Menheere I, Rensen A, Rutjens R, Verharen L, Vloet L. Quality report Consumer Quality Index 'Relatives in the intensive care unit' [Kwaliteitsrapportage Consumer Quality Index 'Naasten op de intensive care']. In.: Lectoraat Acute Intensive Zorg, Hogeschool van Arnhem en Nijmegen; 2015 .
40. Jacqueline: (patient-expert). www.opeenicliggen.nl; 2013.

41. Jongerden IP, Slooter AJ, Peelen LM, Wessels H, Ram CM, Kesecioglu J, Schneider MM, van Dijk D. Effect of intensive care environment on family and patient satisfaction: a before-after study. Intensive Care Med. 2013;39(9):1626-34.

42. Daly BJ, Douglas SL, O'Toole E, Gordon NH, Hejal R, Peerless J, Rowbottom J, Garland A, Lilly C, Wiencek C. Effectiveness trial of an intensive communication structure for families of long-stay ICU patients. CHEST J. 2010;138(6):1340-8.

43. Scheunemann LP, McDevitt M, Carson SS, Hanson LC. Randomized, controlled trials of interventions to improve communication in intensive care: a systematic review. Chest. 2011:139(3):543-54.

44. White DB, Cua SM, Walk R, Pollice L, Weissfeld L, Hong S, Landefeld CS, Arnold RM. Nurse-led intervention to improve surrogate decision making for patients with advanced critical illness. Am J Crit Care. 2012;21(6):396-409.

45. Brackel $\mathrm{M}$. Is he touching my feet? It is stricktly forbidden! [Raakt hij mijn voeten aan? Dat is ten strengste verboden!]. Medisch Contact. 2009;64(50): 2080.

46. Needham DM, Davidson J, Cohen H, Hopkins RO, Weinert C, Wunsch H, Zawistowski C, Bemis-Dougherty A, Berney SC, Bienvenu OJ, et al. Improving long-term outcomes after discharge from intensive care unit: report from a stakeholders' conference. Crit Care Med. 2012;40(2):502-9.

47. Davidson JE, Harvey MA, Schuller J, Black G. Post-intensive care syndrome: what is it and how to help prevent it. American Nurse Today. 2013;8(5):32-8.

48. Radboudumc. Retrieved 14-11-2015 from https://www.radboudumc.nl/Zorg/ Afdelingen/IntensiveCare/Pages/CommunicatieAppvolCe.aspx.

49. Beth Israel Deaconess Medical Center. Retrieved 14-11-2015 from https:// healthmanagement.org/c/icu/news/myicu-app-introduced.

50. Funatic. Retrieved 14-11-2015 from http://www.funatic.nl/wps/portal/ healthcare/icportaal.

51. Hoover H: (patient-expert). www.linkedin.nl; 2015.

52. van Lieshout F, Titchen A, McCormack B, McCance T. Compassion in facilitating the development of person-centred health care practice. J Compassionate Health Care. 2015:2(1):1.

53. van Mol MM, Kompanje EJ, Benoit DD, Bakker J, Nijkamp MD. The prevalence of compassion fatique and burnout among healthcare professionals in intensive care units: a systematic review. PLoS One. 2015:10(8), e0136955.

54. Stamm BH. Measuring Compassion Satisfaction as Well as Fatigue: Developmental History of the Compassion Satisfaction and Fatique Test. In: Figley CR, editor. Treating Compassion Fatigue. New York: Routledge; 2002. p. 107-17.

55. Böckerman P, IImakunnas P. Interaction of working conditions, job satisfaction, and sickness absences: evidence from a representative sample of employees. Soc Sci Med. 2008;67(4):520-8.

56. Haque OS, Waytz A. Dehumanization in medicine causes, solutions, and functions. Perspect Psychol Sci. 2012;7(2):176-86.

57. Vaes J, Muratore M. Defensive dehumanization in the medical practice: A cross-sectional study from a health care worker's perspective. Br J Soc Psychol. 2013;52(1):180-90.

58. Kompanje EJ, van Mol MM, Nijkamp MD. 'I just have admitted an interesting sepsis'. Do we dehumanize our patients? Intens Care Med. 2015;41(12): 2193-2194.

59. Ciufo D, Hader R, Holly C. A comprehensive systematic review of visitation models in adult critical care units within the context of patient-and family-centred care. Int J Evidence Based Healthcare. 2011;9(4):362-87.

60. Cadge W, Hammonds C. Reconsidering detached concern: the case of intensive-care nurses. Perspect Biol Med. 2012;55(2):266-82.

61. Decety J, Smith KE, Norman GJ, Halpern J. A social neuroscience perspective on clinical empathy. World Psychiatry. 2014;13(3):233-7.

62. Decety J, Norman GJ, Berntson GG, Cacioppo JT. A neurobehavioral evolutionary perspective on the mechanisms underlying empathy. Prog Neurobiol. 2012;98(1):38-48.

63. Slatore CG, Hansen L, Ganzini L, Press N, Osborne ML, Chesnutt MS, Mularski RA. Communication by nurses in the intensive care unit: qualitative analysis of domains of patient-centered care. Am J Crit Care. 2012;21(6):410-8. 